\title{
A Study on Water Sanitation Hygiene \& Hand Washing Practices among Mothers Of Under 5 Children Attending Tertiary Care Hospital In Kolkata, India
}

\author{
Dr. Maumita De ${ }^{1}$, Dr. Pranita Taraphdar ${ }^{2}$. \\ ${ }^{I}$ Demonstrator, Department Of Community Medicine, NRS Medical College, Kolkata, India \\ ${ }^{2}$ Associate Professor, Department Of Community Medicine, NRS Medical College, Kolkata, India
}

\begin{abstract}
Safe drinking water, basic sanitation \& hygiene is one of the prime concerns globally. Hand washing with soap is a cost effective way of reducing diarrhoeal disease, acute respiratory infections. But a substantial numbers of women in India have lack of access to these basic facilities \& poor practice of hand washing. An observational cross sectional study was undertaken among 300 mothers of under 5 children attending NRS Medical College during three months period, to assess the water \& sanitation facilities available to them \& their knowledge \& practices regarding hand washing. $51 \%$ of mothers had piped drinking water supply, only $35 \%$ purified water, principally by boiling. $20 \%$ of participants practice open field defaecation in spite of having access to latrines. Hand washing practice of mothers regarding timing \& material used was good. More emphasis must be given to improved access of water, sanitation facilities as well as their utilization \& also on hand hygiene behaviour \& knowledge of mothers.
\end{abstract}

Keywords: hand washing, hygiene, water, sanitation

\section{Introduction}

Communicable diseases continue to be the major contributor to global morbidity and mortality. According to WHO estimates, 3.8 million children aged less than five die each year from diarrhoea and acute respiratory tract infections [1]. Inadequate and unsafe water, poor sanitation, and unsafe hygiene practices are the main causes of diarrhoea, which results in at least 1.9 million under-5 child deaths annually. Diarrhoea morbidity rates are also increasing - children in developing countries suffer from average four to five debilitating bouts of diarrhoea per year, which can cause and exacerbate malnutrition and result in long-term growth stunting. Water, sanitation and hygiene (WASH) are also linked to many other diseases including helminth infections, dracunculiasis, trachoma, cholera, fluorosis and arsenicosis [2].

Estimates from the WHO and UNICEF show that about 1.1 billion people lack access to improved water supplies and 2.6 billion people lack adequate sanitation worldwide [3]. In addition to coverage disparities between countries and regions, there are significant inequities within countries: clear rural-urban disparities as well as coverage and service level disparities between richer and poorer households. Microbiological contamination of water sources is a common problem in many countries and chemical contamination (notably arsenic and fluoride) is increasingly a concern [2].

A safe water supply has been defined as a source which is likely to supply water which is not detrimental to health [4]. Safe water sources include: a household piped water connection; a public stand pipe; a borehole; a protected dug well; a protected spring and a rainwater collection system [5] [6]. In the context of goal 7, target 7C of the MDG's; it seems that sanitation is seen principally as the removal of human excreta or the availability of appropriate facilities for its disposal. For example, in tracking progress of the MDG's the term improved sanitation is used, and it refers to connection of households to a private or sewer septic system (with a soak away), a pour flush latrine, a simple pit latrine, or a ventilated improved pit latrine [4] [5]. Water availability therefore influences the type and functionality of the sanitation facilities which exist and as such it is not unusual for the two to be studied in relation to each other. In terms of hygiene, it may refer to a practice which is either personal or domestic. Personal hygiene refers to the use of water for cleaning parts of the body and domestic hygiene refers to water used to clean items in the home such as food, utensils and floors [7]. As such, WHO and UNICEF have considered hygiene information as an important component of their work on water and sanitation issues [5].

Alongside adequate sanitation, hand washing with soap after stool contact is an important barrier to the faecal-oral spread of diarrhoea because it prevents pathogens from reaching the domestic environment and hence their subsequent ingestion. Hand washing with soap before contact with food and water also reduces the secondary transmission of pathogens from the environment to a new host [8]. Beyond diarrhoeal disease, hand washing is also thought to play a role in reducing the transmission of infections such as pneumonia, influenza, helminths, trachoma, neonatal infections, HIV-associated infections and environmental enteropathies [8] [9]. 
Previous studies have suggested that promoting hand hygiene may be one of the most cost-effective means of reducing the global burden of disease [6].

The Millennium Declaration and the Goals recognize the importance of safe drinking water and sanitation to meet the global commitments. This is now an integral part of Target 10 under Millennium Development Goal 7 on ensuring environmental sustainability, as well as important input for other goals. WASH is a key input for the achievement of universal primary education and reductions in child mortality (Goals 2 and 4) and is directly linked to the eradication of poverty and hunger, the empowerment of women, improvements in maternal health and the reduction of diseases (Goals 1, 3, 5 and 6) [2].

From the 42 studies reporting hand washing prevalence Freeman et al estimate that approximately $19 \%$ of the world population washes hands with soap after contact with excreta. Meta-regression of risk estimates suggests that handwashing reduces the risk of diarrhoeal disease by $40 \%$ (risk ratio $0.60,95 \%$ CI $0.53-0.68$ ) [9]. In a study conducted in Assam, India it was observed that, out of 384 cases, 330 women (86\%) always washed their hands before cooking food while 16 women (4\%) never washed their hands prior to cooking. $93 \%$ of these women always washed hands before eating food, of which $31 \%$ washed with soap [10].

However, there are limited data that have assessed the water, sanitation \& hand hygiene behavior of mothers of under five children in West Bengal, India. Keeping this in view present study was taken up to assess the water \& sanitation facilities available to the mothers of under five children attending the immunization clinic $\&$ their knowledge $\&$ practices regarding hand washing.

\section{Methodology}

An observational, descriptive, cross sectional study was undertaken during three months period(from 11th January to 10th April 2016) among mothers of under five children attending the immunisation clinic of NRS Medical College, Kolkata, India and willing to participate in the study. Sample size was estimated by following way:

According to a cross sectional study in Andhra Pradesh, 71.5\% mothers stated that hand washing was important in prevention of some or the other communicable diseases [11]. Therefore based on anticipated population proportion $\mathrm{P}=71.5 \%$ and assuming confidence level of $95 \%$ and absolute precision of $6 \%$, the minimum required sample size was calculated using the formula [12]:

$$
\begin{array}{rlr}
\mathrm{n} & =\mathrm{Z}_{1-\alpha / 2}^{2} \frac{\mathrm{P}(1-\mathrm{P})}{\mathrm{d}^{2}} & \mathrm{Z}_{1-\alpha / 2}^{2}=1.96 \\
& =\frac{\mathrm{(1.96)2} \times 0.72(1-0.72)}{} & \mathrm{P}=71.5 \%=
\end{array}
$$$$
(0.06) 2 \quad d=6 \%
$$

$$
=215
$$

Assuming $15 \%$ of non responder, minimum sample size was 248 . A total of 300 mothers of under five children were included in the study after interviewing every third mother attending the immunisation clinic of NRS Medical College during study period, using the predesigned, pretested \& semi structured schedule. Prior institutional ethical clearance and informed verbal consent were obtained from the participants who were assured of anonymity and confidentiality of information collected. Independent study variables were age, residence (rural/urban), religion (Hindu/Muslim/Christian), caste (general/SC/ST/OBC), literacy status of mother (illiterate/non-formal/primary/secondary/higher secondary and above), occupation of mother (homemaker/working), type of family (nuclear/Joint), socioeconomic class and dependent variable was water, sanitation hygiene \& hand washing practices. Collected data were analyzed by proportions \& expressed as percentages.

\section{Results}

Majority (79.33\%) of the mothers belonged to the age group of 20-29 years. The proportion of mothers from rural and urban areas was almost equal. More than three fourths $(77.3 \%)$ of the study population was Hindus. Less than half $(44.6 \%)$ of the study population was from unreserved category. Almost one third belonged to scheduled castes. One fifth $(20.6 \%)$ of the study population was either illiterate or non formal literates. Almost half (48.6\%) of mothers were educated up to secondary level \& above. Majority $(86.67 \%)$ of the mothers were home-makers. Almost 2/3rd of the study population (61.3\%) was from nuclear families. $76 \%$ of the study population belonged to social class III or below (according to modified B. G. Prasad scale 2014) [13] [Table 1].

Table 1: Sociodemographic profile of the study population

$(\mathbf{n}=\mathbf{3 0 0})$ 
A Study On Water Sanitation Hygiene \& Hand Washing Practices Among Mothers Of Under ..

\begin{tabular}{|c|c|c|}
\hline Variables & Characters & No $(\%)$ \\
\hline Age Group (years) & $\begin{array}{l}<19 \\
20-29 \\
30-39 \\
\geq 40\end{array}$ & $\begin{array}{l}22(7.33) \\
238(79.33) \\
38(12.67) \\
2(0.67)\end{array}$ \\
\hline Residence & $\begin{array}{l}\text { Rural } \\
\text { Urban }\end{array}$ & $\begin{array}{l}156(52.00) \\
144(48.00)\end{array}$ \\
\hline Religion & $\begin{array}{l}\text { Hindu } \\
\text { Muslim } \\
\text { Christian } \\
\end{array}$ & $\begin{array}{l}232(77.33) \\
66(22.00) \\
2(0.67)\end{array}$ \\
\hline Caste & $\begin{array}{l}\text { General (unreserved) } \\
\text { OBC } \\
\text { SC } \\
\text { ST }\end{array}$ & $\begin{array}{l}134(44.67) \\
52(17.33) \\
96(32.00) \\
18(6.00)\end{array}$ \\
\hline Education & $\begin{array}{l}\text { Illiterate } \\
\text { Non formal literate } \\
\text { Primary } \\
\text { Middle } \\
\text { Secondary } \\
\text { Higher secondary \& above }\end{array}$ & $\begin{array}{l}30(10.00) \\
32(10.67) \\
52(17.33) \\
40(13.33) \\
96(32.00) \\
50(16.67)\end{array}$ \\
\hline Occupation & $\begin{array}{l}\text { Homemaker } \\
\text { Working }\end{array}$ & $\begin{array}{l}260(86.67) \\
40(13.33) \\
\end{array}$ \\
\hline Type of family & $\begin{array}{l}\text { Nuclear } \\
\text { Joint }\end{array}$ & $\begin{array}{l}184(61.33) \\
116(38.67)\end{array}$ \\
\hline Social class & $\begin{array}{l}\text { I }(\geq 5357) \\
\text { II }(2652-5356) \\
\text { III }(1570-2651) \\
\text { IV }(812-1569) \\
\text { V }(<811)\end{array}$ & $\begin{array}{l}6(2.0) \\
66(22.00) \\
64(21.33) \\
106(35.33) \\
58(19.34)\end{array}$ \\
\hline
\end{tabular}

About half $(51.3 \%)$ of the study population received piped drinking water supply. Among those subjects who received piped water supply, majority $(70 \%)$ of the study population received intermittent water supply. About 1/4th (26.6\%) of the study population had to queue for drinking water. Almost half $(51 \%)$ of the subjects who had to queue for drinking water have to wait for10-20 min to receive drinking water and almost one third (30\%) had to wait for 20 minutes or more. Majority $(69.3 \%)$ of the study population used plastic products (bottles \& buckets) for the storage of drinking water. Another significant storage container is metal pots. More than half (55.3\%) of the study population cleaned the storage containers daily. Most of the study population (65\%) used to drink water without any purification at household level. Among half $(47 \%)$ of the study subjects who purified the drinking water, boiling is the common practice for purification [Table 2].

Table 2: Distribution of the study population on water supply, storage \& purification

\begin{tabular}{|l|l|l|}
\hline Variables & Characters & No (\%) \\
\hline Main source of drinking water $(\mathrm{n}=300)$ & Piped Water supply & $154(51.33)$ \\
& Tube well & $132(44.00)$ \\
& Well & $12(4.00)$ \\
& Pond & $2(0.67)$ \\
\hline Type of water supply $(\mathrm{n}=154)$ & Continuous & $46(29.87)$ \\
& intermittent & $108(70.13)$ \\
\hline Queuing for drinking water $(\mathrm{n}=300)$ & Yes & $80(26.67)$ \\
& No & $220(73.33)$ \\
\hline Queuing time (n=80) & $<10$ min & $15(18.75)$ \\
& $10-20$ min & $41(51.25)$ \\
& $20-30$ min & $14(17.5)$ \\
& $>30$ min & $10(12.5)$ \\
\hline Storage container $(\mathrm{n}=300) *$ & Plastic bucket & $122(40.67)$ \\
& Plastic bottles & $86(28.67)$ \\
& Earthen pot & $26(8.67)$ \\
& Metal pot & $80(26.67)$ \\
& Others (glass container etc) & $16(5.33)$ \\
\hline Frequency of cleaning container $(\mathrm{n}=300)$ & Daily & $166(55.33)$ \\
& $>1$ time weekly & $56(18.66)$ \\
Mousehold level (n=106) & Once weekly & $54(18.00)$ \\
& Monthly & $4(1.34)$ \\
& When container is dirty & $20(6.67)$ \\
\hline
\end{tabular}

* Muliple responses 
Majority $(86 \%)$ of the study population had access to sanitary latrines \& $72 \%$ of them had their own latrines. Almost half (44.4\%) of the common latrine users were sharing latrines with 5 or more families. About $17 \%$ of the study population still practiced open field defecation, of which one fifth (10 out of 50) had access to sanitary latrine. Majority $(80 \%)$ of the study population, who practiced open field defecation, cited the reason for this to be absence of sanitary toilets. $46 \%$ of the study population used garbage pit or open area to dispose the stool of under five children. About $1 / 5^{\text {th }}(19.3 \%)$ of the study population used open area for disposing off the solid waste [Table 3].

Table 3: Available sanitation facilities \& solid waste disposal practices of the study population

\begin{tabular}{|l|l|l|}
\hline Variables & Characters & No (\%) \\
\hline Sanitary latrine (n=300) & Present & $260(86.67)$ \\
& Absent & $40(13.33)$ \\
\hline Ownership of Sanitary latrine (n=260) & Owned & $188(72.31)$ \\
& Common & $72(27.69)$ \\
\hline $\begin{array}{l}\text { No. of families using common latrine } \\
(\mathrm{n}=72)\end{array}$ & $\leq 4$ & $40(55.56)$ \\
& $5-9$ & $24(33.33)$ \\
\hline Defecation practice (n=300) & $\geq 10$ & $8(11.11)$ \\
\hline Reason for not using sanitary latrine (n=50) & Open defecation & $50(16.67)$ \\
& Sanitary latrine & $250(83.33)$ \\
\hline Method of disposal of stool of under-5 & Dirty toilet & $40(80.0)$ \\
children (n=300) & Long queue & $4(8.0)$ \\
& Ganitary latrine & $6(12.0)$ \\
\hline & Open field & $124(41.33)$ \\
& Buried & $74(24.67)$ \\
& Others (in river etc) & $64(21.33)$ \\
\hline Disposal of solid waste (n=300) & Garbage pit & $32(10.67)$ \\
& Buried & $162(54.00)$ \\
& Burnt & $52(17.33)$ \\
& Open & $12(4.00)$ \\
& Municipality service & $58(19.33)$ \\
& & $16(5.34)$ \\
\hline
\end{tabular}

Majority $(90.7 \%)$ of the study population washed the kitchen utensils before serving food [Fig 1].

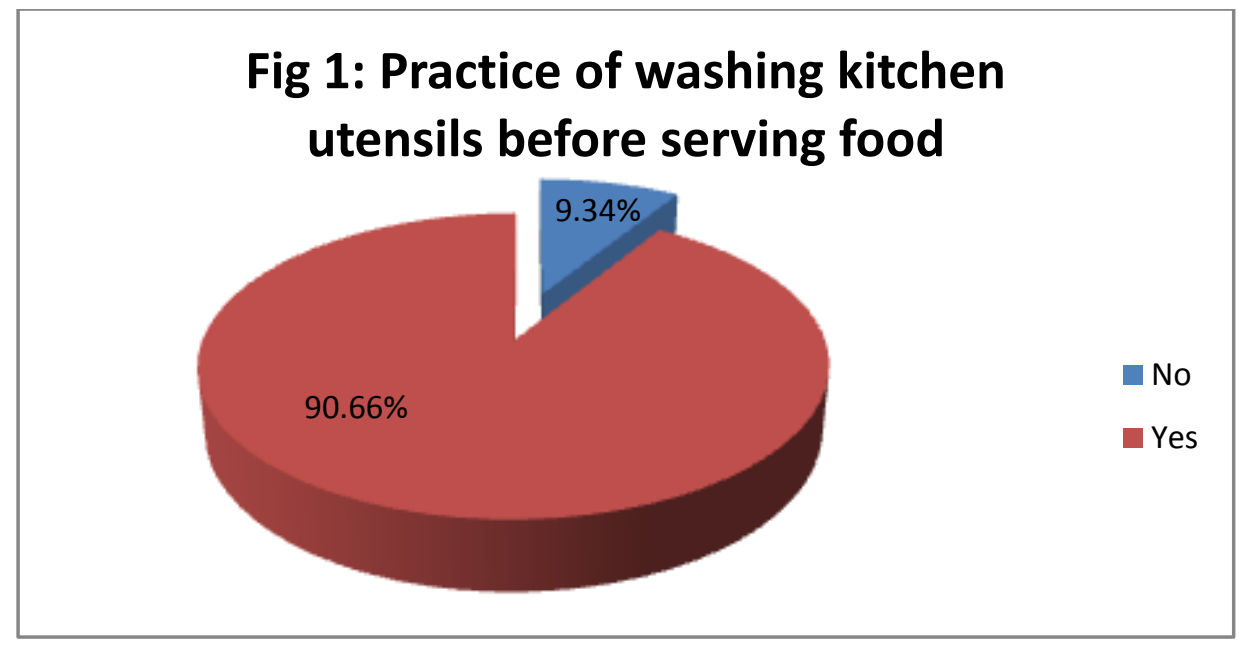

Majority of the study population were aware of the timing of hand washing practices. Majority (74.6\%) of the study population used soap \& water for washing hands. $73 \%$ of the study population believed that hand washing is important for removal of dirt, while $45 \%$ believed it to be for prevention of diseases [Table 4].

Table 4: Hand washing knowledge \& practices of the study population

\begin{tabular}{|l|l|l|}
\hline Variables & Characters & No (\%) \\
\hline Time of washing hands $(\mathrm{n}=300) *$ & After defecation & $300(100.00)$ \\
& After cleaning child's faeces & $296(98.67)$ \\
& Before cooking & $242(80.67)$ \\
& Before eating & $286(95.33)$ \\
& Before breast feeding & $224(74.67)$ \\
\hline Material used for washing hands $(\mathrm{n}=300)$ & Soap \& water & $224(74.67)$ \\
\hline
\end{tabular}


A Study On Water Sanitation Hygiene \& Hand Washing Practices Among Mothers Of Under ..

\begin{tabular}{|l|l|l|}
\hline & Only water & $62(20.67)$ \\
& Ash \& water & $14(4.66)$ \\
\hline $\begin{array}{l}\text { Knowledge of importance of washing hands } \\
(\mathrm{n}=300) *\end{array}$ & Removes dirt & $220(73.33)$ \\
& Prevents disease & $136(45.33)$ \\
\hline
\end{tabular}

* Muliple responses

\section{Discussion}

Clean water and optimum sanitation facilities can prevent the occurrence of various infectious diseases and help in curbing the associated morbidity and mortality. The current study was conducted among mothers of under five children attending the immunisation clinic of NRS Medical College to understand the existing water and sanitation facilities available to the study population \& their knowledge \& practices regarding hand washing. The study revealed majority of the participants were in the age group of 20-29 years, Hindus, reserved category, from nuclear families \& social class III or below, homemakers and educated upto primary level \& above. Similar study conducted in urban slum area of Andhra Pradesh reported most of the mothers were between 20-30 years age group (69.8\%), educated primary \& above (61.9\%), housewives ( $71.9 \%) \&$ from nuclear family $(69.01 \%)$ [11].

The present study found that about half of the study population received piped drinking water supply. Among those subjects who received piped water supply, majority of the study population received intermittent water supply. Almost half (51\%) of the subjects who have to queue for drinking water have to wait for 10-20 min to receive drinking water. Kuberan A et al reported major sources of water procurement in Chennai, India were public tap/stand pipe (42\%), half of the participants $(53 \%)$ having intermittent supply of water \& majority of them $(81 \%)$ required $<5$ min for fetching water from the water outlet [14]. In current study majority of the study population used plastic bottles \& buckets for the storage of drinking water followed by metal pot. More than half of the study population cleaned the storage containers daily. Similarly in Chennai study, $75 \%$ of study participants stored drinking water in wide mouth closed container and most of them cleaned water container daily (70\%) [14]. According to National Family Health Survey (NFHS-3) report, in India approximately 72.7 per cent of the rural population does not use any method of water disinfection [15]. Here also most of the study population $(65 \%)$ drinked water without any purification at household level \& $47 \%$ of the participants who purified water, boiling was the common practice. On the contrary the commonest form of disinfection in Vellore study found was single-point chlorination, using bleaching powder [3]. In a rural area of Chennai $45 \%$ of the participants were not following any methods of water treatment [14]. A Knowledge, Attitudes and Practices (KAP) study addressing water, sanitation and hygiene in a village of Caribbean island of West Indies found that $70.6 \%$ of households engaged in some form of water treatment, principally by boiling[16].

National Family Health Survey (NFHS-3) reported, approximately $74 \%$ of Indians have no sanitary toilet [15]. Interestingly this study indicated that majority $(86 \%)$ of the study population has access to sanitary latrines \& $70 \%$ of them have their own latrines. Almost half $(44.4 \%)$ of the common latrine users were sharing latrines with 5 or more families. About $17 \%$ of the study population still practices open field defecation, of which $1 / 5$ th had access to sanitary latrine. Similarly studies conducted at Chennai \& Udupi district of Manipal, India showed that, majority of the subjects $(75 \%) \&(97.7 \%)$ respectively had latrines in their house [14] [17]. Conversely defaecating in the open fields was a common practice in CMC Vellore study [3]. In present study about $1 / 5$ th of the study population used open area for disposal of solid waste. But according to Kuberan A et al, $47 \%$ of the participants in Chennai discharged their waste in open drainage [14].

One aspect of food hygiene that many people do not address is cleaning serving dishes before taking the food which prevents stray bacteria from transferring from the dish to the food. But surprisingly in this study $90.7 \%$ of the study population washed the kitchen utensils before serving food.

Good hand-washing practices are another neglected area of maintenance of personal hygiene, especially in low-income countries like India. Although people around the world wash their hands with water, very few wash their hands with soap. Multimodal programmes for increasing hand hygiene compliance are now recommended as the most reliable, evidence-based method for ensuring sustainable improvement in hand washing practice [18]. The current study concluded that the mothers of under-5 children practiced hand washing after defecation (100\%), after cleaning child's faeces (99\%), before eating (95\%), before cooking (81\%), before breast feeding $(75 \%)$. Praveen $\mathrm{N}$ et all in their study explored that, hand washing before preparing food \& before serving food is being practiced by $76.8 \%$ \& $57.4 \%$ of mothers [11]. This differs from the study by Ray SK in two communities of eastern India where hand washing was not practiced before "preparing food" and after handling raw vegetables [19]. In a study conducted at coastal Karnataka India, majority of the mothers wash their hands with soap and water after defecation $(90 \%)$ and after cleaning child's bottom $(87.8 \%)$ but fewer women wash their hands before cooking $(31.1 \%)$, before eating $(33.3 \%)$ and before feeding the child $(38.9 \%)$ [19]. It was observed in the present study that majority (4/5th) of the study population used soap \& water for washing hands. In Chennai study $17 \%$ of the participants used plain water or water with ash to clean their hands [13]. In current study $73 \%$ of the study population believed that importance of hand washing is 
removal of dirt while $45 \%$ believed it to be prevention of diseases. On the contrary in Karnataka study almost all the respondents $(96.7 \%)$ stated that hand washing was important for the prevention of diseases \& $45.6 \%$ stated its importance to maintain cleanliness [20].

\section{Conclusion}

The present study explored that half of the study population received piped drinking water supply, but majority did not carry out any household level of purification. Most of them had access to sanitary latrines but unfortunately $20 \%$ of them still practice open field defecation. About one fifth of participants used open area for solid waste disposal. Hence awareness must be generated among population regarding water borne illnesses $\&$ fecal transmission of diseases by various means like vectors etc. However, the translation of knowledge into sustainable behavior needs to be reinforced. Although in this study practice of mothers of under five children regarding timing \& material used for hand washing was good \& majority used soap \& water, but their understanding on importance of hand washing was poor. In resource constraint country like India, in addition to application of other tested interventions worldwide towards improvement in hand washing practices; health workers such as anganwadi workers, ASHA under the aegis of NHM should also be motivated and supported who have better penetration among the communities towards promotion of Information Education \& Communication (IEC) activities to promote proper and regular hand washing practices.

\section{References}

[1]. Murray CJ, Lopez AD. Global mortality, disability, and the contribution of risk factors: Global Burden of Disease Study. Lancet 1997; 349:1436-1442.

[2]. UNICEF WASH Strategy 2006 - 2015. Available from www.unicef.org/about/execboard/files/06-6_WASH_final_ODS.pdf.(Last accessed on 18.05.2016).

[3]. Gopal S, Sarkar R, Banda K, Govindarajan J, Harijan BB, Jeyakumar MB, et al. Study of water supply and sanitation practices in India using geographic information systems: Some design and other considerations in a village setting. Indian J Med Res. March 2009; 129: 233-41

[4]. Hamner S, Tripathi A, Mishra R, Bouskill N, Broadaway SC, Pyle BH, Ford TE. The role of water use patterns and sewage pollution in incidence of water-borne/enteric diseases along the Ganges River in Varanasi, India. International Journal of Environmental Health Research.2006;16(2): 113 - 32.

[5]. WHO/UNICEF Global water supply and sanitation assessment 2000 Report. Geneva. Available from: http://www.who.int/water_sanitation_health/monitoring/jmp2000.pdf (Last accessed on18.05.2016).

[6]. Cairncross S, Valdmanis V. 2006. Water supply, sanitation, and hygiene promotion . In Disease control priorities in developing countries, 2nd ed., ed. D. T. Jamison, J. G. Breman, A. R. Measham, G. Alleyne, M. Claeson, D. B. Evans, P. Jha, A. Mills, and P. Musgrove., 771-792. New York: Oxford University Press. Available from: http://www.ncbi.nlm.nih.gov/books/NBK11755/ (Last accessed on18.05.2016).

[7]. Esrey SA, Potash JB, Roberts L, and Shiff C. 1991. Effects of improved water supply and sanitation on ascariasis, diarrhoea, dracunculiasis, hookworm infection, schistosomiasis, and trachoma. Bulletin of the World Health Organization 1991;69(5): 609-21.

[8]. Curtis V, Cairncross S, Yonli R. Domestic hygiene and diarrhoea-pinpointing the problem. Tropical Medicine and International Health.2000;5(1): 22-32.

[9]. Freeman MC, Clasen T, Brooker SJ, Akoko DO \& Rheingans R. (2013) The impact of a school-based hygiene, water quality and sanitation intervention on soil-transmitted helminth reinfection: a cluster randomized trial. The American Journal of Tropical Medicine and Hygiene. 2013; 89: 875-83.

[10]. Thapa G, Barua A, Dowerah S. Study of Hand Washing Practices among Mothers Having Children Under 5 years of Age. International Journal of Basic and Applied Medical Sciences. 2015; 5 (2): 201- 04.

[11]. Yerpude PN, Jogdand KS, Sumra NA. A Cross-Sectional Study on Hand Washing Practices among Mothers in an Urban Slum Area. International Journal of Health Sciences \& Research. Oct 2014; 4(10): 1-5.

[12]. Lwanga SK, Lemeshow S: Sample Size Determination in Health Studies: A Practical Manual. Geneva: World Health Organization; 1991. P 25.

[13]. Mangal A, Kumar V, Panesar S, Talwar R, Raut D , Singh S. Updated BG Prasad Socioeconomic Classification, 2014: A Commentary. Indian Journal of Public Health. January-March 2015; 59 (1): $42-4$

[14]. Kuberan A, Singh AK, Kasav JB, Prasad S, Surapaneni KM, Upadhyay V, Joshi A. Water and sanitation hygiene knowledge, attitude, and practices among household members living in rural setting of India. J Nat Sci Biol Med. 2015 Aug; 6(Suppl 1): 69-74.

[15]. International Institute for Population Sciences (IIPS) and Macro International. National Family Health Survey (NFHS-3), 2005-06: India: Volume I, Mumbai: IIPS; 2007.

[16]. Montoute MC, Cashman A. A knowledge, attitudes and practices study on water, sanitation and hygiene in Anse La Raye Village, Saint Lucia. Cave Hill Campus, Barbados : Centre for Resource Management and Environmental Studies (CERMES), The University of the West Indies; 2015. Available from www.cavehill.uwi.edu/.../montoute_cashman_2015_kap_wa... (Last accessed on18.05.2016).

[17]. Reshma, Mamatha SP, Manjula. A Descriptive Study to Assess the Knowledge and Practice Regarding Water, Sanitation and Hygiene among Women in Selected Villages of Udupi District. NUJHS. 2016 March; 6(1): 21-8. Available from: www.nitte.edu.in/journal/march2016/o7.pdf (Last accessed on18.05.2016).

[18]. Larson EL, Early E, Cloonan P, Sugrue S, Parides M. An organizational climate intervention associated with increased handwashing and decreased nosocomial infections. Behavioral Medicine 2000; 26(1):14-22.

[19]. Ray SK, Zaman FA, Laskar BN. Hand washing practices in two communities of two states of eastern India: An Interventional Study. Indian J Pub Health 2010; 54:32-38.

[20]. Aithal KS, Ogorchukwu MJ, Prabhu V, Shriyan P, Yadav UN. Hand washing Knowledge and Practice among mothers of under-five children in coastal Karnataka, India - A cross sectional study. Int J Med Health Sci. Oct 2014; 3(4): $266-71$. 